\title{
Chemical and biochemical study of industrially produced San Simón da Costa smoked semi-hard cow's milk cheeses: Effects of storage under vacuum and different modified atmospheres
}

\author{
J. I. Garabal, ${ }^{* 1}$ P. Rodríguez-Alonso, ${ }^{*}$ D. Franco, ${ }^{*} \dagger$ and J. A. Centenoł \\ *Dairy Science and Technology Laboratory, Agricultural Research Center of Mabegondo (CIAM), Xunta de Galicia, 15318 Abegondo, Spain \\ †Meat Technology Center of Galicia (CETECA), 32900 Ourense, Spain \\ ¥Food Technology Laboratory, Faculty of Science, University of Vigo, 32004 Ourense, Spain
}

\begin{abstract}
Two batches of smoked, semi-hard (ripened for 45 d) San Simón da Costa cow's milk cheeses with Protected Designation of Origin were used to investigate the chemical, biochemical, and sensorial parameters that may be affected by modified-atmosphere packaging. Cheeses were packaged for $45 \mathrm{~d}$ as follows: vacuum packaging, packaging in $100 \% \mathrm{~N}_{2}$, packaging in a gas mixture of $20 \% \mathrm{CO}_{2} / 80 \% \mathrm{~N}_{2}$, and packaging in a gas mixture of $50 \% \mathrm{CO}_{2} / 50 \% \mathrm{~N}_{2}$. The San Simón da Costa cheeses were characterized by high contents of lactic, oxalic, and citric organic acids. The main free amino acids found were isoleucine, phenylalanine, serine, valine, lysine, and glutamic acid, and the most abundant volatile compounds included ethanol, diacetyl, 2-butanol, isopropyl alcohol, furfural, acetaldehyde, 2-butanone, acetone, and 2-methylfuran. Modified atmospheres appeared to alter the ripening processes by affecting lipolysis, as indicated by the lower concentrations of butyric and propionic acids compared with control cheeses. In addition, modified-atmosphere packaging altered the proteolysis processes, yielding higher amounts of branched-chain alcohols. The results revealed that storage under modified atmosphere contributes to the accumulation of several compounds probably derived from smoke, including aldehydes such as 2-furancarboxaldehyde (furfural), alcohols such as 2-methoxyphenol (guaiacol), ketones such as 2-cyclopenten-1-one, and esters such as methyl furancarboxylate, which were negatively correlated with flavor. Vacuum packaging was the most useful technique in terms of preserving the sensory quality of San Simón da Costa Protected Designation of Origin cheeses. Considering the current demands for packaged portions of food at the distribution and retail levels and the potential health risks associated with some smoke-derived compounds usu-
\end{abstract}

Received September 18, 2009.

Accepted January 12, 2010.

${ }^{1}$ Corresponding author: jose.ignacio.garabal.sanchez@xunta.es ally present in some smoked foods, the results obtained in this study may be of special interest to the cheese industry.

Key words: smoked cheese, modified-atmosphere packaging, chemical and biochemical compounds, sensory analysis

\section{INTRODUCTION}

Modified-atmosphere packaging (MAP) has generated great interest in the manufacture of food products as a means of preserving high-quality fresh products, improving the image of the product, extending the commercial shelf-life, and minimizing the use of additives and preservatives. Moreover, packaging in plastic pouches prevents dehydration and consequent weight loss, as well as absorption of undesirable odors from the environment (for reviews see Robertson, 1993; Hotchkiss et al., 2006). Pouches are usually filled with atmospheres low in oxygen and high in carbon dioxide and nitrogen, which have been shown to slow down respiration rate, reduce microbial growth, and retard enzymatic changes (Hotchkiss et al., 2006). Carbon dioxide has bacteriostatic and fungistatic effects, whereas nitrogen acts principally as filler, preventing package collapse (Robertson, 1993). Modified-atmosphere packaging is also expected to affect beneficial microorganisms involved in sensory attributes of foods during storage. It is obvious that many interactions between microorganisms occur in cheese in relation to flavor formation; however, our knowledge of this area is limited because of the complexity of the cheese microbial ecosystem.

Some studies of the effect of MAP on the shelf-life and quality of hard and semi-hard cheeses as well as fresh cheeses have been carried out (e.g., Robertson, 1993; Eliot et al., 1998; González-Fandos et al., 2000; Kristensen et al., 2000; Juric et al., 2003; Hotchkiss et al., 2006), and MAP is accepted worldwide for use with cheeses. Nevertheless, it has been reported that the use of MAP with high percentages of $\mathrm{CO}_{2}$ may have a 
detrimental effect on the sensory properties, especially flavor, of semi-hard or hard cheeses such as portioned Parmigiano-Reggiano cheese (Romani et al., 2002), sliced Sams $\varnothing$ cheese (Juric et al., 2003), and grated Graviera cheese (Trobetas et al., 2008). Gas mixtures with high percentages of $\mathrm{N}_{2}$ are considered most suitable for preserving the sensory attributes of these types of cheeses.

Sensory characteristics are very important in cheese analysis, especially with respect to quality control (Bertozzi and Panari, 1993), but become of major importance when dealing with cheeses with Protected Designation of Origin (PDO) status. San Simón da Costa (SSC) is a semi-hard cow's milk cheese produced in Galicia (northwest Spain) and which has PDO status. Milk used for cheese manufacture is curdled with calf rennet at 31 to $33^{\circ} \mathrm{C}$ for 30 to $40 \mathrm{~min}$. The curd is cut into 5- to $12-\mathrm{mm}$ long pieces and washed with pasteurized water at 33 to $35^{\circ} \mathrm{C}$. The cheeses are molded, pressed at approximately 2 to $3 \mathrm{~kg} / \mathrm{cm}^{2}$ for at least $3 \mathrm{~h}$, and then salted in brine (14 to $17 \% \mathrm{NaCl}$ ) for at least $24 \mathrm{~h}$. The cheeses are then ripened for at least $45 \mathrm{~d}$ at $6 \pm 2{ }^{\circ} \mathrm{C}$, and finally smoked just before delivery to market. Industrial cheeses are made from pasteurized milk, and the smoking operation is carried out, as in traditional raw-milk cheese making, with barkless birch wood (Betula celtiberica) for 2 to $7 \mathrm{~h}$. The cheese has a characteristic shape intermediate between pear-shaped and bullet-shaped, terminating at the top in a point, and typically ranges in weight between 0.8 and $1.5 \mathrm{~kg}$. The outer layer of the cheese, 1 to $3 \mathrm{~mm}$ deep, is a yellow-ochre color on the surface and somewhat oily. The edible part of the cheese is of fine texture, fatty, semi-hard, semi-elastic, and dense, between white and yellow in color, cuts easily, and has a characteristic smoky aroma and flavor. Eyes should not be present in the mass or must be in low number. Gross composition and $\mathrm{pH}$ must be as follows: $\geq 55 \% \mathrm{DM} ; 45$ to $60 \%$ fat in DM; pH between 5.0 and 5.6 (MAPA, 2005).

Because of its moderate $(\leq 45 \%)$ moisture content and the smoking procedures after ripening, SSC cheese is expected to be microbiologically safe and is normally sold unpackaged. Nevertheless, because of ongoing international market expansion, there is now a demand for packaging at distribution and selling points. Sales of SSC cheese have increased by $60 \%$ in the last $7 \mathrm{yr}$, with an annual production of $349,000 \mathrm{~kg}$ during 2008 (about $€ 3$ million in global value of sales at selling points). There is an increasing demand for portioned SSC cheeses (half portions or wedges), but no studies have been carried out with respect to the sensory features of these portions or of their shelf-life at the distribution and retail levels.
There is little scientific information about SSC cheese, particularly with respect to the microbial flora in raw milk cheeses (García-Fontán et al., 2001; Garabal et al., 2008; Rodríguez-Alonso et al., 2008). Some chemical and biochemical characteristics of industrial SSC cheeses have been reported recently (Nhuch et al., $2008 \mathrm{a}, \mathrm{b})$ but no information was provided about the sensorial quality or smoking operations. Moreover, it is unknown if MAP can preserve the typical sensory quality of this traditional PDO cheese. Thus, the aims of the present work were 1) to characterize industrial SSC cheeses from a chemical and biochemical point of view, including analysis of organic acids, free amino acids and volatile compounds, and 2) to evaluate the effects of packaging of portioned SSC cheese under different types of atmosphere, on the chemical and biochemical parameters, and on the sensory quality of the cheeses.

\section{MATERIALS AND METHODS}

\section{Collection, Packaging, Storage, and Sampling of the Cheeses}

Two batches of 72 SSC industrial (pasteurized milk) PDO certified cheeses $(1,000 \pm 50 \mathrm{~g}$ in weight), each one produced from the same vat of milk, were provided by a local dairy plant known to manufacture premiumgrade products. Cheeses were purchased immediately after completion of the 45-d ripening period and subsequent smoking.

Fifty cheeses from each batch were cut into 4 wedges of approximately equal weight (225 to $275 \mathrm{~g}$ ) to provide a total of 200 wedges. The wedges were packaged in plastic pouches composed of multilayer polyesterpolyvinyl chloride $(13 \mu \mathrm{m}$ thick $)$ and polyethylene (80 $\mu \mathrm{m}$ thick) (Polyskin X, Amcor Flexibles Hispania S.L., Barcelona, Spain), with an oxygen permeability of $<9$ $\mathrm{cm}^{3} / \mathrm{m}^{2}$ per day at $0 \%$ relative humidity $(\mathbf{R H})$ and $23^{\circ} \mathrm{C}$, and a water vapor permeability of $<4 \mathrm{~g} / \mathrm{m}^{2}$ per day at $90 \% \mathrm{RH}$ and $38^{\circ} \mathrm{C}$.

The pouches were evacuated, flushed, and then double heat-sealed by using an EV-15-1-CD packaging machine (Technotrip S.A., Terrasa, Spain) with gas injection. The 4 different atmosphere treatments included 1) vacuum $97 \%$ (vol/vol) packaged (VP) cheese wedges; 2) cheese wedges packaged in $100 \%$ ( $\mathrm{vol} / \mathrm{vol}$ ) $\mathrm{N}_{2}$ (NP); 3) cheese wedges packaged in $20 \%$ (vol/vol) $\mathrm{CO}_{2} / 80 \%$ (vol/vol) $\mathrm{N}_{2}$ (CN1P); and 4) cheese wedges packaged in $50 \% \mathrm{CO}_{2} / 50 \% \mathrm{~N}_{2}(\mathbf{C N 2 P})$. Each treatment was applied to 50 samples. Nitrogen and $\mathrm{CO}_{2} / \mathrm{N}_{2}$ gas mixtures were supplied by Carburos Metálicos S.A. (Barcelona, Spain).

Of the remaining 22 whole cheeses from each batch, 3 were sampled for physicochemical, microbiological, 
and biochemical analyses before storage (time 0), and 4 were set aside for sensory analysis at time 0 . The other 15 cheeses served as controls, and were stored aerobically in a dark cold-storage room for $45 \mathrm{~d}$, together with the 200 packaged cheese wedges. Storage conditions were $85 \pm 3 \% \mathrm{RH}$ and $6 \pm 2^{\circ} \mathrm{C}$, simulating retail conditions.

The aerobically stored whole cheeses (control cheeses), and the packaged cheese wedges (VP, NP, CN1P, and $\mathrm{CN} 2 \mathrm{P}$ cheeses) were analyzed after $45 \mathrm{~d}$ of storage (time 45). Before physicochemical, microbiological, and sensory analyses, cheeses were equilibrated at room temperature $\left(20 \pm 2^{\circ} \mathrm{C}\right)$. Physicochemical and microbiological analyses were carried out on refrigerated (4 $\pm 1^{\circ} \mathrm{C}$ ) samples within $24 \mathrm{~h}$. Biochemical analyses were carried out on frozen samples $\left(-30 \pm 1^{\circ} \mathrm{C}\right)$ wrapped in aluminum foil. The outside layer of 0.5 to $1 \mathrm{~cm}$ in depth (including the cheese rind) was removed before sampling for physicochemical, microbiological, and biochemical testing.

The data reported in this paper represent means of values from 2 replicated experiments (2 batches) in which all analyses were performed on triplicate samples, except sensory analyses, which were carried out in duplicate.

\section{Physicochemical and Microbiological Analysis}

The SSC cheeses were analyzed for moisture content [International Dairy Federation (IDF) Standard 4A; IDF, 1982], fat content (IDF Standard 152A; IDF 1997a), and protein content (IDF Standard 20A: IDF, 1986) before storage (time 0). After $45 \mathrm{~d}$ of storage (time 45), control cheeses and packaged cheeses were analyzed for moisture content.

The $\mathrm{pH}$ of the cheese was measured with a digital $\mathrm{pH}$ meter (model 507, Crison, Barcelona, Spain) equipped with a probe for solids. Titratable acidity was determined by the method proposed by the AOAC (AOAC, 1990).

Mesophilic microorganisms were enumerated on plate count milk agar (Oxoid, Basingstoke, UK) following the pour-plate method and incubated at $30 \pm 1^{\circ} \mathrm{C}$ for $3 \mathrm{~d}$. Yeasts and molds were enumerated on rose bengal chloramphenicol agar (Merck, Darmstadt, Germany) at $25 \pm 1{ }^{\circ} \mathrm{C}$ for $5 \mathrm{~d}$. Sample preparation was carried out in accordance with IDF Standard 122C (IDF, 1996), although the first dilution was 1:5 (wt/vol; $10 \mathrm{~g}$ of cheese $+40 \mathrm{~mL}$ of $2 \%$ sodium citrate).

\section{Gas Composition of Package Headspace}

The concentrations of $\mathrm{O}_{2}$ and $\mathrm{CO}_{2}$ were measured before physicochemical and microbiological analysis to verify packaging atmospheres for each treatment, with a Gas Data portable dual analyzer (model PCO2 Plus/100, Gas Data Ltd., Coventry, UK). A rubber septum (Systech Instr. Ltd., Thame, UK) was glued onto the surface of each pouch and pierced with a 23 -gauge needle connected to the headspace analyzer. The headspace analyzer gave a direct reading of the percentage of $\mathrm{O}_{2}$ and $\mathrm{CO}_{2}$ in the pouch headspace. Gas concentration measurements were taken at the beginning and end of the packaging runs and averaged for each type of gas; packages were then randomized with respect to storage treatments.

\section{Determination of Organic Acids}

The organic acids (OA) acetic, butyric, citric, formic, lactic, orotic, oxalic, pyruvic, propionic, succinic, and uric acids, were determined by reversed phase-HPLC following the method proposed by Tormo and Izco (2004). Analysis was carried out on a HPLC Breeze System (Waters, Milford, MA), consisting of a 1525 binary HPLC pump, a 717 plus autosampler, and a 2487 2-channel UV detector set at $210 \mathrm{~nm}$, operated with Breeze software. The separation was performed on an Atlantis dC18 column (Waters, $250 \mathrm{~mm} \times 4.6$ $\mathrm{mm}, 5-\mu \mathrm{m}$ particle size). Results were expressed as milligrams of OA per kilogram of cheese.

\section{Determination of Free Amino Acids}

Sample extracts obtained previously for OA were also used to study the contents of ammonium and the free amino acids (FAA) Ala, Arg, Asp, Glu, Gly, His, Ile, Leu, Lys, Met, Phe, Pro, Ser, Tyr, Thr, and Val. Separations were carried out on a AccQ-Tag column (3.9 $\mathrm{mm} \times 150 \mathrm{~mm}$, particle size $4 \mu \mathrm{m}$; Waters) operated at a flow rate of $1.0 \mathrm{~mL} / \mathrm{min}$, and at $37^{\circ} \mathrm{C}$. The gradient profile and composition of the mobile phase was adapted from the methodology developed by Van Wandelen and Cohen (1997), and according to the AccQ-Tag method instructions (Waters). Detection was accomplished by fluorescence with excitation at $250 \mathrm{~nm}$ and emission at $395 \mathrm{~nm}$. Amino acids were identified by retention time with an amino acid standard. Results were expressed as milligrams of FAA per kilogram of cheese.

\section{Determination of Volatile Compounds}

Volatile compounds were determined by GC-MS, according to the method described by Rodríguez-Alonso et al. (2009) with some modifications. The analysis was carried out on an automatic dynamic headspace apparatus (Tekmar Dohrmann 3100 Sample Concentrator, Tekmar, Cincinnati, OH) connected to a GC-MS (Agi- 
lent 6890N Network GC System and Agilent 5953 Mass Selective Detector; Agilent Technologies, Santa Rosa, CA). Operating conditions on a DB-Wax column (60 $\mathrm{m}$ length $\times 0.32 \mathrm{~mm}$ i.d.; $0.25-\mu \mathrm{m}$ film thickness) were as follows: carrier gas (helium; Carburos Metálicos) at $1 \mathrm{~mL} / \mathrm{min}$, initial temperature $32^{\circ} \mathrm{C}$ for $7 \mathrm{~min}, 6^{\circ} \mathrm{C} / \mathrm{min}$ up to $180^{\circ} \mathrm{C}, 10^{\circ} \mathrm{C} / \mathrm{min}$ up to $225^{\circ} \mathrm{C}$, and maintained for 2 min. The mass detector was run in scanning mode from 19 to $250 \mathrm{amu}$, with the ion source at $230^{\circ} \mathrm{C}$ and ionization voltage at $70 \mathrm{eV}$. Data were obtained by use of MSD Productivity Chemstation Software (Agilent). Identification of hexane, heptane, dimethyl disulfide, benzaldehyde, butanal, 3-methyl-1-butanal, acetone, 2,3-butanedione, ethanol, 3-methyl-1-butanol, 2-butanol, 1-hexanol, isopropyl alcohol, acetic acid, butyric acid, 3-methyl butyric acid, ethyl esters of linear fatty acids $\mathrm{C} 3-\mathrm{C} 12$, and the reported smoke derived compounds 2-butoxyethyl acetate, 2-furancarboxaldehyde, 2-methylfuran, 2-methoxyphenol, phenol, ethylbenzene, 1,4-dimethylbenzene, and trichloromethane was based on their retention times and on the relative abundances of ions selected for their identification, verified with authentic standard compounds. The other volatile compounds reported in this study were tentatively identified by comparison of their spectra with those contained in the NIST98 (National Institute of Standards and Technology, Gaithersburg, MD) and Wiley 275 (Wiley and Sons Inc., Weinheim, Germany) libraries. Relative abundances of compounds were expressed as percentages of the peak areas in relation to the borneol (internal standard) peak area. Only volatile compounds showing the highest mean relative abundances $(>1.0)$ were considered for analysis. Nonaromatic, nonalicyclic, and nonheterocyclic hydrocarbons were further excluded for MAP analysis because of their relatively high odor threshold values.

\section{Chemicals}

The analytical standards used in this study were obtained from Sigma-Aldrich (St. Louis, MO), and gradient HPLC-grade acetonitrile from Scharlab Science (Barcelona, Spain). Milli-Q water (Millipore Co., Bedford, MA) was used to prepare buffers and the stock solutions of each standard compound and samples.

\section{Sensory Evaluation}

Sensory evaluation was performed at the sensory room of the Lamas de Abade Catering College (Santiago de Compostela, Spain) by a panel of 10 members responsible for judging the sensory quality of Galician industrial cheeses with PDO status. The sensory judges were formally trained assessors (ISO, 1994; IDF, 1997b), with experience ( 5 to 10 yr of sensory evaluation practice) in evaluating the product.

Cheeses were transported in portable refrigerators $\left(4 \pm 1^{\circ} \mathrm{C}\right)$ and were equilibrated at room temperature $\left(20 \pm 2^{\circ} \mathrm{C}\right)$ for $2 \mathrm{~h}$ before the sensory analysis sessions. Sensory analyses were carried out at time 0 (cheeses before storage) and time 45 (control and packaged cheeses). Cheeses at time 0 and control cheeses at time 45 were cut into 4 wedges of approximately equal weight and placed in plastic pouches (Polyskin $\mathrm{X}$ ), which were sealed before being transported. All cheeses were transported in portable refrigerators $(4 \pm$ $\left.1^{\circ} \mathrm{C}\right)$ and were equilibrated at room temperature $(20 \pm$ $2^{\circ} \mathrm{C}$ ) for $2 \mathrm{~h}$ before the sensory analysis sessions. The pouches containing the packaged (treated) cheeses were opened, and cheeses were immediately placed in sealed plastic pouches just before being given to the panelists for evaluation. All cheese samples (225 to $275 \mathrm{~g}$ ) were coded with randomly chosen 3 -digit numbers and presented in random order to panelists in individual booths with white fluorescent light (IDF, 1997b). The panelists opened the pouches containing each cheese sample, and used unsalted crackers and water to cleanse their palates between samples. All the cheeses were analyzed in duplicate in 2 different sessions.

The judges evaluated the following attributes: appearance (color of the rind and of the cheese mass, cut appearance, and possible presence of eyes), odor (evaluated on the rind and on the cheese mass), texture (evaluated by finger pressing and by chewing the cheese mass in the mouth), acid taste, and flavor (evaluated by chewing and salivating the cheese mass in the mouth). Each attribute was scored on a scale of 1 to 7 , where a score of 1 corresponded to those characteristics completely opposing the standards of the industrial PDO cheese, and a score of 7 corresponded to those characteristics that are wholly consistent with the standards of the industrial PDO cheese. The results were expressed as a mean score by the whole panel for each attribute and cheese.

An overall score was obtained by adding the weighted scores for appearance, texture, and flavor attributes (IDF, 1997b), by multiplying the scores by 1,3 , and 6 , respectively. Thus, an excellent industrial PDO cheese would receive a total score of 70 . It was also arbitrarily considered that cheeses with an overall score below 40 should be rejected. The sensory cards included an "Observations" section, in which the judges were asked to note all the descriptors they considered useful for defining the cheese attributes.

\section{Statistical Analysis}

Data corresponding to samples analyzed at time 45 were subjected to ANOVA and where statistical differ- 
Table 1. Physicochemical characteristics ( $\mathrm{pH}$, acidity, and gross composition), organic acids, and free amino acids in San Simón da Costa cheeses ripened for $45 \mathrm{~d}$ (prestorage)

\begin{tabular}{lc}
\hline Item & Mean $\pm \mathrm{SE}$ \\
\hline Physicochemical parameters & \\
pH & $5.25 \pm 0.172$ \\
Acidity (\% lactic acid) & $0.021 \pm 0.003$ \\
DM (\%, wt/wt) & $56.7 \pm 0.63$ \\
Fat/DM (\%, wt/wt) & $55.5 \pm 2.40$ \\
Protein/DM (\%,wt/wt) & $38.6 \pm 1.72$ \\
Organic acids (mg/kg) & \\
Lactic & $6,858.7 \pm 721.25$ \\
Oxalic & $1,430.9 \pm 250.84$ \\
Citric & $703.6 \pm 173.62$ \\
Acetic & $512.3 \pm 199.76$ \\
Formic & $429.0 \pm 24.19$ \\
Butyric & $410.0 \pm 123.32$ \\
Succinic & $288.8 \pm 57.89$ \\
Propionic & $341.5 \pm 13.86$ \\
Pyruvic & $187.6 \pm 45.36$ \\
Uric & $28.2 \pm 2.69$ \\
Orotic & $9.6 \pm 1.42$ \\
Total organic acids & $11,200.1 \pm 830.17$ \\
Free AA (mg/kg) & \\
Ile & $1,268.4 \pm 193.57$ \\
Ser & $653.1 \pm 69.99$ \\
Phe & $637.0 \pm 93.82$ \\
Val & $478.1 \pm 59.67$ \\
Lis & $469.5 \pm 57.97$ \\
Glu & $452.7 \pm 217.86$ \\
His & $415.4 \pm 51.98$ \\
Pro & $399.7 \pm 105.63$ \\
Arg & $244.3 \pm 59.11$ \\
Tyr & $211.0 \pm 99.17$ \\
Met & $201.2 \pm 17.84$ \\
Gly & $196.8 \pm 26.93$ \\
Asp & $188.4 \pm 34.72$ \\
Leu & $173.4 \pm 27.54$ \\
Ala & $170.6 \pm 28.86$ \\
Thr & $136.7 \pm 50.73$ \\
Ammonium & $573.1 \pm 122.68$ \\
Total free AA ${ }^{1}$ & $6,296.4 \pm 846.19$ \\
\hline & \\
Total & \\
\hline &
\end{tabular}

${ }^{1}$ Total sum of free AA without ammonium.

ences were noted, differences among the distinct groups (control and packaged cheeses groups) were determined by the Duncan's test. Differences were considered significant at $P<0.05$. Correlation analysis for flavor and chemical/biochemical variables that differed among the groups was performed by use of a bivariate (2-tailed significance) correlation test. Pearson coefficients were calculated, and differences were considered significant at the $P<0.05$ and $P<0.01$ levels. The selected traits that correlated with flavor were subjected to principal components analysis (Varimax rotation, Kaiser normalization; data not shown), and hierarchical cluster analysis (Ward's method, squared Euclidean distance) was then performed on the principal components analysis values to group the samples. The cluster solution was confirmed by calculation of a Wilks' lambda value. All statistical procedures were performed with the SPSS Win 15.0 program (SPSS Inc., Chicago, IL).

\section{RESULTS AND DISCUSSION}

\section{Physicochemical and Microbiological Analyses and Headspace Gas Composition}

Gross composition (DM and fat/DM) of SSC cheeses at time 0 (ripened for $45 \mathrm{~d}$ but prestorage) is shown in Table 1. The data fulfilled the requirements of the PDO regulations.

As expected, aerobic storage of control cheeses for 45 $\mathrm{d}$ led to loss of weight (estimated mean value of weight loss was $8.1 \%$ ) and the moisture content decreased to $39.8 \%$ (Table 2). The mean moisture content of packaged cheeses was higher than that of control cheeses, although differences were only significant $(P<0.05)$ for VP cheese (Table 2). This is consistent with the findings of other authors who have reported that different gas mixtures did not significantly influence the moisture contents or the weight losses in hard or semihard cheeses packaged under modified atmospheres (Romani et al., 2002; Juric et al., 2003; Trobetas et al., 2008).

The mean $\mathrm{pH}$ of the SSC cheeses at time 0 was 5.25 and the mean titratable acidity was $0.021 \%$ lactic acid (Table 1), although higher $\mathrm{pH}$ values were observed for all cheeses groups after storage for $45 \mathrm{~d}$ (Table 2). This finding may be attributed to proteolysis and associated formation of amines and ammonium. There was no clear correlation between $\mathrm{pH}$ and titratable acidity; the lowest $\mathrm{pH}(P<0.05)$ (mean value of 5.32) corresponded to the control cheeses and the highest mean acidity ( $0.027 \%$ lactic acid) corresponded to the CN2P cheeses. The presence of $\mathrm{CO}_{2}$ in the headspaces of the $\mathrm{CO}_{2}$-treated cheeses was expected to cause a decrease in $\mathrm{pH}$ and an increase in acidity because of its dissolution in cheese and the formation of carbonic acid (González-Fandos et al., 2000). Nevertheless, $\mathrm{CO}_{2}$ is mainly absorbed on the surface of food, which may lead to acidification of some spots on the surface rather than in the total mass of the sample (Dermiki et al., 2008).

High total counts of mesophilic microorganisms were obtained at time $0\left(7.6 \times 10^{8} \mathrm{cfu} / \mathrm{g}\right)$ with a slight decreasing trend, particularly in the $\mathrm{CN} 2 \mathrm{P}$ atmosphere $\left(1.0 \times 10^{8} \mathrm{cfu} / \mathrm{g}\right)$ after $45 \mathrm{~d}$ of storage (data not shown). On the other hand, yeasts and molds were only detected in very low numbers (mean counts $<50 \mathrm{cfu} / \mathrm{g}$; data not shown) on some plates of control and NP cheeses. These findings are consistent with the findings of several authors who have reported that MAP with high $\mathrm{CO}_{2}$ concentrations are very effective for inhibiting bacteria, molds, and yeasts (Eliot et al., 1998; Hotchkiss et al., 2006; Dermiki et al., 2008).

Comparison of the $\mathrm{CO}_{2}$ observed in the pouches before and after storage showed that the mean percentage 
Table 2. Physicochemical and biochemical (organic acids and free AA) characteristics showing significant differences between unpackaged control and packaged San Simón da Costa cheeses after 45 d of storage (means $\pm \mathrm{SE}$ )

\begin{tabular}{|c|c|c|c|c|c|}
\hline \multirow[b]{2}{*}{ Item } & \multirow{2}{*}{$\begin{array}{l}\text { Unpackaged } \\
\text { control cheeses }\end{array}$} & \multicolumn{4}{|c|}{ 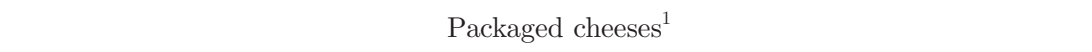 } \\
\hline & & VP & NP & CN1P & $\mathrm{CN} 2 \mathrm{P}$ \\
\hline \multicolumn{6}{|l|}{ Physicochemical characteristics } \\
\hline $\mathrm{pH}$ & $5.32^{\mathrm{b}} \pm 0.081$ & $5.47^{\mathrm{a}} \pm 0.115$ & $5.45^{\mathrm{a}} \pm 0.080$ & $5.46^{\mathrm{a}} \pm 0.125$ & $5.40^{\mathrm{ab}} \pm 0.113$ \\
\hline Acidity (\% lactic acid) & $0.025^{\mathrm{ab}} \pm 0.004$ & $0.026^{\mathrm{ab}} \pm 0.005$ & $0.022^{\mathrm{b}} \pm 0.004$ & $0.023^{\mathrm{ab}} \pm 0.003$ & $0.027^{\mathrm{a}} \pm 0.001$ \\
\hline Moisture $(\%, \mathrm{wt} / \mathrm{wt})$ & $39.8^{\mathrm{b}} \pm 0.96$ & $41.9^{\mathrm{a}} \pm 1.25$ & $41.6^{\mathrm{ab}} \pm 1.58$ & $41.4^{\mathrm{ab}} \pm 1.55$ & $41.2^{\mathrm{ab}} \pm 1.53$ \\
\hline Estimated weight loss (\%) & 8.1 & 3.2 & 4.0 & 4.5 & 4.9 \\
\hline Lactic acid & $6,469.7^{\mathrm{a}} \pm 310.99$ & $6,234.1^{\mathrm{ab}} \pm 634.53$ & $5,334.9^{\mathrm{c}} \pm 671.04$ & $5,532.0^{\mathrm{bc}} \pm 749.30$ & $5,484.9^{\mathrm{c}} \pm 624.08$ \\
\hline Oxalic acid & $1,515.4^{\mathrm{c}} \pm 150.56$ & $2,446.0^{\mathrm{a}} \pm 225.78$ & $2,022.6^{\mathrm{b}} \pm 455.13$ & $1,543.0^{\mathrm{c}} \pm 249.21$ & $2,236.0^{\mathrm{ab}} \pm 112.56$ \\
\hline Butyric acid & $979.9^{\mathrm{a}} \pm 220.03$ & $839.7^{\mathrm{ab}} \pm 248.53$ & $653.4^{\mathrm{b}} \pm 201.64$ & $705.0^{\mathrm{b}} \pm 336.37$ & $831.5^{\mathrm{ab}} \pm 232.08$ \\
\hline Propionic acid & $985.1^{\mathrm{a}} \pm 92.20$ & $538.7^{\mathrm{bc}} \pm 174.49$ & $474.5^{\mathrm{d}} \pm 150.66$ & $664.0^{\mathrm{b}} \pm 212.64$ & $529.7^{\mathrm{bc}} \pm 66.09$ \\
\hline Citric acid & $802.6^{\text {ab }} \pm 78.78$ & $870.7^{\mathrm{a}} \pm 165.86$ & $631.5^{\mathrm{c}} \pm 160.57$ & $666.9^{\mathrm{bc}} \pm 108.41$ & $848.2^{\mathrm{a}} \pm 177.58$ \\
\hline Formic acid & $435.3^{\mathrm{a}} \pm 8.20$ & $348.1^{\mathrm{b}} \pm 32.00$ & $320.4^{\mathrm{b}} \pm 17.86$ & $348.8^{\mathrm{b}} \pm 22.15$ & $325.8^{\mathrm{b}} \pm 40.05$ \\
\hline Succinic acid & $260.2^{\mathrm{c}} \pm 22.06$ & $339.9^{b} \pm 68.27$ & $312.1^{\mathrm{bc}} \pm 58.31$ & $254.9^{\mathrm{c}} \pm 112.40$ & $426.3^{\mathrm{a}} \pm 58.46$ \\
\hline \multicolumn{6}{|c|}{ 12, } \\
\hline Gly & $362.0^{\mathrm{a}} \pm 19.74$ & $328.4^{\mathrm{ab}} \pm 23.23$ & $299.0^{\mathrm{bc}} \pm 16.92$ & $345.1^{\mathrm{a}} \pm 14.64$ & $273.9^{\mathrm{c}} \pm 7.75$ \\
\hline Thr & $47.4^{\mathrm{a}} \pm 9.33$ & $0.0^{\mathrm{b}} \pm 0.00$ & $0.0^{\mathrm{b}} \pm 0.00$ & $0.0^{\mathrm{b}} \pm 0.00$ & $0.0^{\mathrm{b}} \pm 0.00$ \\
\hline Ammonium & $1,064.3^{\mathrm{a}} \pm 17.14$ & $1,051.2^{\mathrm{a}} \pm 89.20$ & $873.1^{\mathrm{b}} \pm 24.70$ & $1,020.0^{\mathrm{ab}} \pm 86.55$ & $929.1^{\mathrm{ab}} \pm 65.70$ \\
\hline Total free $\mathrm{AA}^{3}$ & $11,013.7 \pm 289.13$ & $10,671.8 \pm 1,089.53$ & $9,856.6 \pm 927.41$ & $10,022.8 \pm 964.75$ & $9,482.2 \pm 818.11$ \\
\hline
\end{tabular}

${ }^{\mathrm{a}-\mathrm{c}}$ Means within a row with different superscripts differ significantly $(P<0.05)$.

${ }^{1}$ Vacuum packaged cheeses (VP); cheeses packaged under $100 \% \mathrm{~N}_{2}(\mathrm{NP})$; cheeses packaged under $20 \% \mathrm{CO}_{2} / 80 \% \mathrm{~N}_{2}(\mathrm{CN} 1 \mathrm{P})$; and cheeses packaged under $50 \% \mathrm{CO}_{2} / 50 \% \mathrm{~N}_{2}(\mathrm{CN} 2 \mathrm{P})$.

${ }^{2}$ Not tested.

${ }^{3}$ Total free AA without ammonium.

of this gas decreased $(-10.7 \%)$ in the headspaces of the CN2P cheeses, whereas it increased slightly in those of the CN1P and NP cheeses $(+8.3 \%$ and $+13.8 \%$, respectively; Table 2). The low concentrations of $\mathrm{CO}_{2}$ detected in the $\mathrm{CN} 2 \mathrm{P}$ headspaces may be attributed to dissolution of $\mathrm{CO}_{2}$ in the cheese matrix, to $\mathrm{CO}_{2}$ consumption by anaerobic microorganisms, or to a loss of $\mathrm{CO}_{2}$ through the barrier film (Eliot et al., 1998; Juric et al., 2003; Trobetas et al., 2008). On the contrary, most increases in $\mathrm{CO}_{2}$ concentrations in the NP and the CN1P headspaces may be caused by Strecker degradation and reduction of sugars, although microbial metabolism plus some oxidative and enzymatic reactions involving oxygen might be involved (Eliot et al., 1998; Trobetas et al., 2008). Increases in $\mathrm{CO}_{2}$ have also been reported during storage of semi-hard and hard cheeses packed under modified atmospheres (Kristensen et al., 2000; Trobetas et al., 2008). There were no significant differences in $\mathrm{O}_{2}$ content among the packaged cheeses, and the mean values were between $0.17 \%$ and $0.2 \%$ (data not shown). These concentrations are similar to those reported for sliced semi-hard Sams $\varnothing$ cheese $(0.000$ to $0.130 \%$; Juric et al., 2003) and sliced Havarti cheese (mean value of $0.023 \%$; Kristensen et al., 2000) stored in 20 to $100 \% \mathrm{CO}_{2}$ atmospheres for $21 \mathrm{~d}$.

\section{Organic Acids}

The initial step in cheese ripening is the conversion of lactose to lactate, which is achieved by lactic acid bacteria (LAB); however, other OA may appear in cheese as products of enzyme-mediated hydrolysis of milk fat because of growth and metabolism of microorganisms. Before packaging (time 0), the most abundant OA in the cheeses were lactic acid (about $62 \%$ of total OA), oxalic acid (about $13 \%$ of total OA), and citric acid (about $6 \%$ of total OA), with uric acid and orotic acid detected at very low levels (Table 1 ).

Lactic acid, a major product of the fermentation of lactose by LAB, reaches levels between 1,940 and $17,400 \mathrm{mg} / \mathrm{kg}$ in dairy products (Bevilacqua and Califano, 1989). Residual lactose not fermented during the earlier stages of ripening eventually gets used by nonstarter lactic acid bacteria (NSLAB), leading to the formation of D-lactate as a major end-product (Turner and Thomas, 1980). The unexpected extremely high concentrations of oxalic acid found in the SSC cheeses may be related to the pasture on which the cows were feeding (Franceschi and Nakata, 2005). The low contents of orotic acid may be caused by the intense washing of the curd carried out during cheese making (Larson and 
Hegarty, 1979) or utilization by microorganisms as a growth factor during ripening (González de Llano et al., 1996).

Organic acid contents have been considered indicators of microbial metabolism, and the associated profile is useful in terms of identifying the ripening stage (Akalin et al., 2002). Concentrations of OA (means and SD) for which significant differences were found among the different groups of cheeses after $45 \mathrm{~d}$ of storage are shown in Table 2. Total contents of OA at $45 \mathrm{~d}$ were higher $(P$ $<0.05$ ) in control and VP cheeses (Table 2). In general, the main types of OA detected after the different treatments were the same as those detected at the beginning of the study (lactic, oxalic, and citric acids), although butyric and propionic acids were also present in high amounts after storage (Table 2). On the contrary, uric acid (16.9 to $24.4 \mathrm{mg} / \mathrm{kg}$; data not shown) and orotic acid ( 4.8 to $7.5 \mathrm{mg} / \mathrm{kg}$; data not shown) were detected at the lowest levels and the contents were lower than those detected at time 0 .

Butyric acid is probably released from triglycerides through the action of nonspecific esterases and lipases of starter lactococci and secondary microflora (González de Llano et al., 1996). Moreover, butyric acid may be produced from fats or be the result of proteolysis and subsequent deamination of casein (Califano and Bevilacqua, 2000) and may be transformed on demethylation to propionic and formic acids. As in the present study, increases in butyric acid during ripening of SSC pasteurized cheese have previously been reported (Nhuch et al., 2008b). Moreover, increases in butyric and propionic acids have been reported during ripening of other cow's milk cheeses (Bevilacqua and Califano, 1989; Akalin et al., 2002; Lues and Bekker, 2002; Upreti et al., 2006; Nhuch et al., 2008a). Lower concentrations of butyric, propionic, and formic acids in MAP cheeses compared with SSC control cheeses suggest a reduction in the initial formation of butyric acid in the packaged cheeses. This reduction may be related to a decrease in the degree of lipolysis, as noted in other studies on MAP cheeses (Robertson, 1993; Dermiki et al., 2008).

Citric acid was detected in higher amounts $(P<$ 0.05) in the VP and CN2P cheeses than in the NP and $\mathrm{CN} 1 \mathrm{P}$ cheeses. Moreover, oxalic and pyruvic acids were also detected in significantly higher amounts in the VP cheeses (Table 2). Citric and pyruvic acids are intermediary metabolites and generally show irregular changes during cheese ripening (Akalin et al., 2002; Lues and Bekker, 2002; Upreti et al., 2006). Moreover, citrate can be used as a substrate by the starter lactococci to produce pyruvic and acetic acids (Adda et al., 1982). Pyruvate may also be produced by mesophilic LAB through the glycolytic pathway, and may act as a substrate of several metabolic reactions with the forma- tion of formic acid, ethanol, and carbonyl compounds such as diacetyl and acetoin (Adda et al., 1982). On the other hand, $\mathrm{LAB}$ can fix $\mathrm{CO}_{2}$ using pyruvate carboxylase and convert pyruvate to oxaloacetate, which may be further converted to citrate through the action of citrate synthase (Upreti et al., 2006).

Additionally, succinic acid, which was detected in higher amounts $(P<0.05)$ in $\mathrm{CN} 2 \mathrm{P}$ cheeses (Table 2$)$ could also be generated by lactobacilli, either by citrate metabolism or by degradation of serine (Skeie et al., 2007).

\section{Free Amino Acids}

Lactic acid bacteria are nutritionally fastidious microorganisms, which are nevertheless able to hydrolyze milk peptides to FAA. Certain FAA are extremely important in terms of flavor and taste development; for example, Arg is related to bitterness, whereas Pro, Ser, and Asn are related to sweetness (Pappa and Sotirakoglou, 2008). The most abundant FAA in SSC cheeses were Ile (about $20 \%$ of total FAA), Ser (about $10 \%$ of total FAA), and Phe (about $10 \%$ of total FAA); Thr, Ala, and Leu were detected at the lowest levels (Table 1 ). This FAA profile was different from that reported in a recent study (Nhuch et al., 2008b), in which Glu, Trp, and Leu were the most abundant FAA at 45 and 60 $\mathrm{d}$ of ripening. These 3 amino acids together with Asn and Gln in pasteurized milk SSC cheese (Nhuch et al., 2008b) or together with Arg and Phe in raw milk SSC cheese (Nhuch et al., 2008a) accounted for $60 \%$ of the total FAA. A considerable variation in composition between manufacturers, probably because of variations in manufacturing parameters, was observed by the latter authors. These studies did not provide any information about the sensorial quality of the cheese under study. Moreover, variations in the use of different commercial starters and in the methods used for FAA detection may result in different FAA profiles.

The branched-chain amino acids Ile and Val and the aromatic amino acid Phe are recognized precursors of key aroma compounds (Yvon and Rijnen, 2001). Isoleucine, Phe, and Ser, together with Glu, Lys, and Val (the next most abundant FAA in SSC), have been reported as the principal FAA in cow's milk Parmigiano-Reggiano (Battistotti and Corradini, 1993) and Ragusano (Fallico et al., 2004) cheeses. Glutamic acid, Val, Phe, and Ile were also the main FAA in Mahón cow's milk cheese ripened for 4 mo (Polo et al., 1985). Unlike in the present study, Leu was also found to be one of main FAA in several hard and semi-hard cow's milk cheeses (Battistotti and Corradini, 1993; Gorostiza et al., 2004; Pappa and Sotirakoglou, 2008). Arginine, which has been reported to be responsible for an unpleasant bit- 
tersweet taste in cheese (Lemieux and Simard, 1992), was detected at high levels $(244.3 \mathrm{mg} / \mathrm{kg})$ in SSC cheeses.

At the end of the storage time, the total amounts of FAA in all cheese samples were approximately 2 times higher than those observed at the beginning of the study (Table 1 and Table 2), suggesting a high rate of proteolysis during the $45 \mathrm{~d}$ of storage. The main FAA detected at the end of the storage period were the same as those detected at the beginning of the study (Ile, Phe, and Ser; Table 2; some data not shown). On the contrary, Thr was only detected in control cheeses and Tyr was determined in mean amounts lower than 200 $\mathrm{mg} / \mathrm{kg}$ (data not shown).

The amounts of Phe, Ser, and Gly were higher $(P$ $<0.05)$ in control cheeses compared with MAP conditions (Table 2; statistics not shown), and Thr was only detected in the control cheeses (Table 2). Variations in Ser contents may have been the result of the different growth rates of lactobacilli able to degrade Ser to yield OA (Skeie et al., 2007). Moreover, some reversible reactions with Tyr-Phe, together with transamination reactions by NSLAB (Gummalla and Broadbent, 2001), may cause changes in these amino acids. On the other hand, Thr can be converted to acetaldehyde and Gly by means of threonine aldolase (Marshall and Cole, 1983). Thus, microbial degradation involving several different enzymes may be favored by low concentrations of oxygen in the modified atmospheres tested.

Although the highest total amounts of FAA were observed in the control and VP cheeses, no differences were found among groups for this trait (Table 2). Vercelino et al. (1996) reported a lack of any effect of the $\mathrm{CO}_{2}$ package on proteolysis during storage. In other studies (González-Fandos et al., 2000; Dermiki et al., 2008), a higher degree of proteolysis has been reported in air-packaged and vacuum-packaged cheeses than in $\mathrm{CO}_{2}$-treated cheeses. González-Fandos et al. (2000) related the higher proteolytic index in vacuum-packaged cheeses to the higher counts of microorganisms in the cheeses.

\section{Volatile Compounds}

The conversion of amino acids to aroma compounds is mainly initiated by amino acid transamination, which requires an $\alpha$-keto acid as an amino group acceptor for the aminotransferases. Keto acids produced by transamination can further be transformed to various aroma compounds. Thus, catabolism of amino acids is a major contributor to flavor formation in ripened cheeses (Yvon and Rijnen, 2001).

Two hundred twenty volatile compounds were identified from the chromatograms of SSC cheeses ripened for
$45 \mathrm{~d}$ (time 0 ), but only 67 compounds were present with mean relative abundances higher than 1.0 (Table 3). When the amounts were compared with those observed in control cheeses after $45 \mathrm{~d}$ of storage (time 45; Table 4 , some data not shown in tables), higher amounts $(P$ $<0.05$; statistics not shown) were observed at time 0 for furfural, 5-methylfurfural, and 2-methyl-1-propanal among aldehydes; ethanol, 2-methyl-2-propanol, 2-propen-1-ol, 1-pentanol and guaiacol among alcohols; diacetyl, 2-butanone, acetoin, 3-methyl-3-buten-2-one, 2,3-pentanedione, cyclopentanone, 2-methyl-2-cyclopenten-1-one, 1-(2-furanyl)-ethanone, 2-heptanone, 3-methyl-2-butanone, 2-cyclopenten-1-one, and 2-methylcyclopentanone among ketones; toluene, pxylene, ethylbenzene, $\beta$-pinene, ethyl-cyclopentane, and 1,3,5-trimethylbenzene among aromatic and alicyclic hydrocarbons; and 2-methylfuran, furan, benzofuran, 2-(2-propenyl)-furan, and 2-methylbenzofuran among heterocyclic compounds. On the other hand, lower amounts $(P<0.05)$ were found at time 0 for 3 -methyl1-butanal, hexanal, nonanal, and benzaldehyde among aldehydes; 1-propanol, cyclopentanol, 3-methyl-2buten-1-ol, 2-heptanol, and 3-methyl-2-butanol among alcohols; acetone among ketones; methyl butanoate, and ethyl hexanoate among esters, and pyridine among heterocyclic compounds.

Carbonyl derivatives, cyclopentane derivatives, and benzene derivatives are the most abundant compounds probably derived from smoke (Jónsdóttir et al., 2008). Most compounds probably derived from smoke were found at higher relative abundance in the SSC before storage than at time 45 for control cheeses (Table 3 and Table 4). Some hydrocarbons such as alkyl substituted benzene, naphthalene derivatives, and xylenes may also be derived from the pasture (Barron et al., 2007), and chloroform, toluene, and other benzene derivatives may occur in cheeses as artifacts from adsorbents used in volatile extraction, as a result of packaging material, or as result of environmental contamination during freezing of the samples (Barron et al., 2007; Félix et al., 2008). In this regard, the cheese samples of this study were frozen at $-30^{\circ} \mathrm{C}$ for up to 6 mo. Among the furans, the highest mean abundances corresponded to furfural and 2-methylfuran (Table 3). The furans present in cheese may be result of a Maillard reaction between an amino acid and a sugar, although the effect of pasteurization on the content of furans in cheese is still unclear. Furans such as 2-methylfuran and principally benzofuran have been detected by other authors in Idiazábal cheese (Barron et al., 2007) and Abondance cheese (Bugaud et al., 2001). Phenolic compounds were detected in generally low abundances in SSC cheeses (Table 3), and were mainly represented by guaiacol, 3-methylphenol, and phenol. Phenols show very low 
Table 3. Relative abundances of the main volatile compounds in San Simón da Costa cheeses ripened for $45 \mathrm{~d}$

\begin{tabular}{|c|c|}
\hline Compound & Mean \pm SE \\
\hline \multicolumn{2}{|l|}{ Aldehydes } \\
\hline 2-Furancarboxaldehyde (furfural) ${ }^{1,2}$ & $408.2 \pm 223.55$ \\
\hline Acetaldehyde & $243.1 \pm 33.99$ \\
\hline 5-Methylfurfural ${ }^{1,2}$ & $33.8 \pm 26.35$ \\
\hline 3-Methyl-1-butanal ${ }^{2}$ & $30.5 \pm 21.06$ \\
\hline Hexanal & $24.0 \pm 22.10$ \\
\hline Propanal & $11.6 \pm 1.76$ \\
\hline 2-Methyl-1-propanal & $9.8 \pm 6.09$ \\
\hline Butanal $^{2}$ & $6.9 \pm 1.48$ \\
\hline Nonanal & $3.9 \pm 3.84$ \\
\hline Benzaldehyde $^{1,2}$ & $3.4 \pm 0.53$ \\
\hline \multicolumn{2}{|l|}{ Alcohols } \\
\hline Ethanol $^{2}$ & $20,953.5 \pm 2,207.00$ \\
\hline 2-Butanol ${ }^{2}$ & $778.2 \pm 233.51$ \\
\hline Isopropyl alcohol $^{2}$ & $672.6 \pm 133.30$ \\
\hline 2-Methyl-2-propanol & $154.5 \pm 14.42$ \\
\hline 1-Butanol & $139.3 \pm 19.28$ \\
\hline 1-Propanol & $75.4 \pm 12.67$ \\
\hline 3-Methyl-1-butanol ${ }^{2}$ & $33.9 \pm 9.13$ \\
\hline 2-Butoxyethanol ${ }^{1}$ & $32.0 \pm 6.87$ \\
\hline 2-Propen-1-ol & $23.3 \pm 3.92$ \\
\hline 3-Methyl-2-butanol & $18.7 \pm 1.68$ \\
\hline 1-Pentanol & $11.2 \pm 8.94$ \\
\hline 2-Methoxyphenol (guaiacol) $)^{1,2}$ & $10.8 \pm 6.13$ \\
\hline 2-Methyl-1-propanol & $6.8 \pm 6.18$ \\
\hline 2-Furanmethanol (furfuryl alcohol) $)^{1}$ & $4.5 \pm 2.15$ \\
\hline 3-Methylphenol & $3.6 \pm 3.94$ \\
\hline Phenol $^{1,2}$ & $2.0 \pm 1.54$ \\
\hline 2-Heptanol & $1.1 \pm 1.61$ \\
\hline \multicolumn{2}{|l|}{ Esters } \\
\hline Ethyl acetate $^{2}$ & $23.9 \pm 5.58$ \\
\hline 2-Butoxyethyl acetate ${ }^{1,2}$ & $19.5 \pm 13.62$ \\
\hline Methyl acetate & $18.0 \pm 15.28$ \\
\hline Ethyl hexanoate $^{2}$ & $1.6 \pm 1.04$ \\
\hline \multicolumn{2}{|l|}{ Sulfur compounds } \\
\hline Dimethyl disulfide ${ }^{2}$ & $30.9 \pm 6.79$ \\
\hline Carbon disulfide & $12.3 \pm 6.32$ \\
\hline Dimethyl sulfide & $4.6 \pm 2.77$ \\
\hline \multicolumn{2}{|l|}{ Ketones } \\
\hline 2,3-Butanedione (diacetyl) ${ }^{2}$ & $1,148.8 \pm 237.49$ \\
\hline 2-Butanone & $207.7 \pm 67.61$ \\
\hline Acetone $^{2}$ & $187.6 \pm 63.06$ \\
\hline 3-Hydroxy-2-butanone (acetoin) & $102.8 \pm 23.64$ \\
\hline 3-Methyl-3-buten-2-one & $83.0 \pm 11.71$ \\
\hline 2,3-Pentanedione & $41.2 \pm 23.51$ \\
\hline Cyclopentanone $^{1}$ & $37.1 \pm 4.21$ \\
\hline 2-Methyl-2-cyclopenten-1-one ${ }^{1}$ & $31.7 \pm 5.72$ \\
\hline 1-(2-Furanyl)-ethanone ${ }^{1}$ & $30.4 \pm 3.24$ \\
\hline 2-Heptanone & $24.6 \pm 7.43$ \\
\hline 3-Methyl-2-butanone & $22.5 \pm 6.20$ \\
\hline 2-Cyclopenten-1-one ${ }^{1}$ & $19.4 \pm 5.87$ \\
\hline 2-Nonanone & $8.8 \pm 1.44$ \\
\hline 2-Methylcyclopentanone ${ }^{1}$ & $8.07 \pm 6.11$ \\
\hline \multicolumn{2}{|l|}{ Hydrocarbons ${ }^{3}$} \\
\hline Trichloromethane (chloroform) $)^{1,2}$ & $265.8 \pm 103.57$ \\
\hline Methylbenzene (toluene) $)^{1,2}$ & $149.6 \pm 25.89$ \\
\hline Alpha-pinene $e^{1}$ & $15.5 \pm 0.62$ \\
\hline 1,4-Dimethylbenzene ( $p$-xylene $)^{1,2}$ & $13.4 \pm 8.77$ \\
\hline Ethylbenzene $^{1,2}$ & $11.2 \pm 2.98$ \\
\hline Beta-pinene $^{1}$ & $5.6 \pm 1.42$ \\
\hline Ethyl-cyclopentane $^{1}$ & $5.9 \pm 0.88$ \\
\hline $1,3,5$-Trimethylbenzene ${ }^{1}$ & $5.1 \pm 3.22$ \\
\hline 1-Ethyl-2-methyl-benzene ${ }^{1}$ & $3.4 \pm 3.25$ \\
\hline 1-Ethyl-3-methyl-benzene ${ }^{1}$ & $2.1 \pm 2.89$ \\
\hline 1,2 -Dimethylbenzene ${ }^{1}$ & $1.1 \pm 0.97$ \\
\hline
\end{tabular}

Table 3 (Continued). Relative abundances of the main volatile compounds in San Simón da Costa cheeses ripened for $45 \mathrm{~d}$

\begin{tabular}{lc}
\hline Compound & Mean $\pm \mathrm{SE}$ \\
\hline Heterocycles $^{4}$ & \\
2-Methylfuran $^{1,2}$ & $107.1 \pm 30.64$ \\
Furan $^{1}$ & $25.5 \pm 22.38$ \\
Benzofuran $^{1}$ & $5.9 \pm 1.15$ \\
2-(2-Propenyl)-furan $^{1}$ & $5.8 \pm 3.60$ \\
Pyridine $^{1}$ & $3.5 \pm 2.51$ \\
2-Methylbenzofuran $^{1}$ & $3.3 \pm 1.78$ \\
2-Pentylfuran $^{1}$ & $1.5 \pm 1.71$ \\
2,5-Dihydrofuran $^{1}$ & $1.1 \pm 1.31$ \\
\hline
\end{tabular}

${ }^{1}$ Compounds probably originating from smoke.

${ }^{2}$ Volatile compounds verified with authentic standard compounds.

${ }^{3}$ Only aromatic and alicyclic hydrocarbons probably derived from smoke are listed.

${ }^{4}$ The group includes nonsubstituted furans and other heterocyclic compounds probably derived from smoke.

sensory threshold values (Rychlik et al., 1998) and are considered the main cause of the smoky flavor (Maga, 1988).

Only 35 volatile compounds showed differences $(P$ $<0.05$ ) among the different MAP treatments at time 45 (Table 4). Of these, aldehydes are transitory compounds that may be easily reduced to the corresponding alcohols in the low redox environment of cheese, and therefore, low amounts of aldehydes are expected in ripened cheeses (Rodríguez-Alonso et al., 2009). Among the MAP cheeses, the branched-chain aldehyde 3-methyl-1-butanal was the most abundant aldehyde, reaching the highest abundance in CN2P cheeses (Table 4). This compound has also been reported as the major aldehyde (about $50 \%$ of the total aldehydes) in shredded Cheddar cheese packaged in $100 \% \mathrm{CO}_{2}$ (Colchin et al., 2001). 3-Methylbutanal has been suggested to originate from Strecker degradation of Leu and contributes considerably to aroma because of its synergistic effect with alcohols (Yvon and Rijnen, 2001; Rodríguez-Alonso et al., 2009). Relative abundances of the linear-chain aldehydes nonanal, propanal, and butanal were significantly higher in NP cheeses than in at least one of the groups of $\mathrm{CO}_{2}$-treated cheeses. Other authors have reported a lack of or lower amounts of aldehydes in hard cheeses packed under $\mathrm{N}_{2}$ than in aerobically stored cheeses, suggesting that most of the aldehydes were derived from lipid oxidation (Colchin et al., 2001; Trobetas et al., 2008).

Alcohols were the most abundant chemical group in SSC cheeses (Table 3). The highest amounts of primary alcohols (1-butanol, 1-pentanol, and 1-hexanol) and branched-chain alcohols (2-methyl-2-propanol, 3-methyl-1-butanol, 3-methyl-2-butanol, and 2-ethyl1-hexanol) were found in the $\mathrm{CO}_{2}$-treated cheeses (Table 4). Colchin et al. (2001) also found higher 
Table 4. Relative abundances of the main volatile compounds showing major differences among unpackaged control and packaged San Simón da Costa cheeses after $45 \mathrm{~d}$ of storage (means $\pm \mathrm{SE}$ )

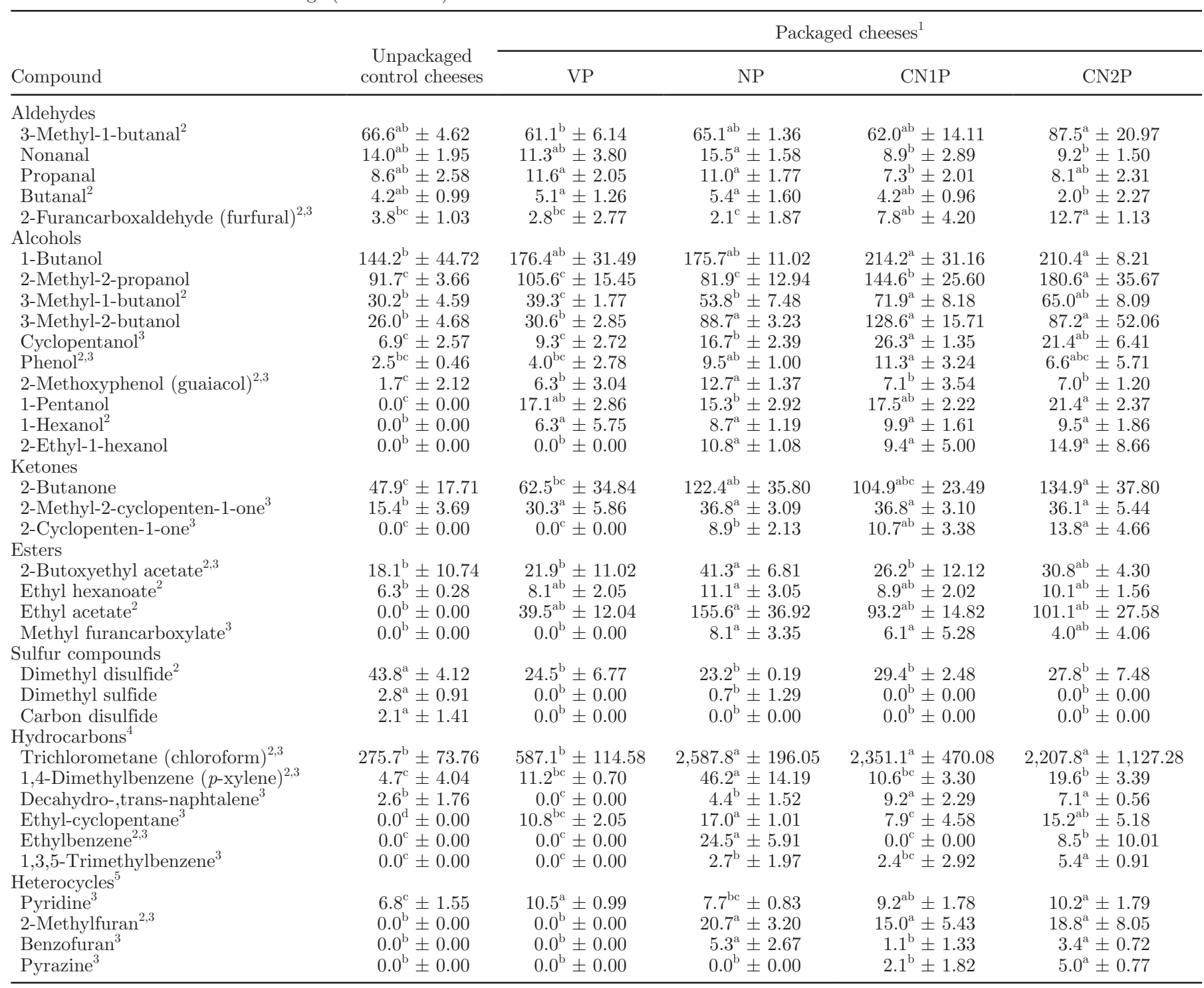

${ }^{\mathrm{a}-\mathrm{d}}$ Means within a row with different superscripts differ significantly $(P<0.05)$.

${ }^{1}$ Vacuum-packaged cheeses (VP); cheeses packaged under $100 \% \mathrm{~N}_{2}(\mathrm{NP})$; cheeses packaged under $20 \% \mathrm{CO}_{2} / 80 \% \mathrm{~N}_{2}(\mathrm{CN} 1 \mathrm{P})$; and cheeses packaged under $50 \% \mathrm{CO}_{2} / 50 \% \mathrm{~N}_{2}(\mathrm{CN} 2 \mathrm{P})$.

${ }^{2}$ Volatile compounds verified with authentic standard compounds.

${ }^{3}$ Compounds probably derived from smoke.

${ }^{4}$ Only those aromatic and alicyclic hydrocarbons probably derived from smoke are listed.

${ }^{5}$ The group includes nonsubstituted furans and other heterocyclic compounds probably derived from smoke.

concentrations of primary alcohols in Cheddar cheese stored under $\mathrm{CO}_{2}(100 \%)$ than cheese stored under $\mathrm{N}_{2}$. The most intense reducing conditions of $\mathrm{CO}_{2}$-treated cheeses may have favored reduction of aldehydes to their corresponding alcohols, such as the reduction of the aldehyde 3-methylbutanal to the branched-chain alcohol 3-methylbutanol (Adda et al., 1982; RodríguezAlonso et al., 2009). The lower amounts of most of the alcohols in the control and VP cheeses also support this suggestion.

Among the ketones, the highest abundances of 2-butanone were found in NP and $\mathrm{CO}_{2}$-treated cheeses. Diacetyl, which is mainly produced from citrate metabolism, may be reduced to acetoin, which in turn may be reduced by NSLAB to 2-butanone (Urbach, 1993). Tentatively identified alicyclic ketones 2-cyclopenten- 
Table 5. Sensory scores for unpackaged control and packaged San Simón da Costa cheeses after 45 d of storage (means \pm SE)

\begin{tabular}{|c|c|c|c|c|c|}
\hline Attribute & $\begin{array}{l}\text { Unpackaged } \\
\text { control cheeses }\end{array}$ & \multicolumn{4}{|c|}{ Packaged cheeses ${ }^{1}$} \\
\hline Appearance & $5.2^{\mathrm{a}} \pm 0.29$ & $4.7^{\mathrm{ab}} \pm 0.52$ & $4.3^{\mathrm{b}} \pm 0.58$ & $4.3^{\mathrm{b}} \pm 0.42$ & $4.7^{\mathrm{ab}} \pm 0.27$ \\
\hline Texture & $3.8^{\mathrm{bc}} \pm 0.58$ & $4.7^{\mathrm{a}} \pm 0.52$ & $3.6^{\mathrm{c}} \pm 0.58$ & $4.3^{\mathrm{ab}} \pm 0.26$ & $4.3^{\mathrm{ab}} \pm 0.29$ \\
\hline Acid taste & $4.8^{\mathrm{ab}} \pm 0.29$ & $5.3^{\mathrm{a}} \pm 0.65$ & $3.8^{\mathrm{b}} \pm 0.35$ & $3.5^{\mathrm{b}} \pm 0.71$ & $4.3^{\mathrm{ab}} \pm 0.58$ \\
\hline Flavor & $4.6^{\mathrm{a}} \pm 0.29$ & $4.9^{\mathrm{a}} \pm 0.38$ & $3.9^{\mathrm{b}} \pm 0.25$ & $3.4^{\mathrm{bc}} \pm 0.55$ & $3.1^{\mathrm{c}} \pm 0.22$ \\
\hline
\end{tabular}

${ }^{\mathrm{a}-\mathrm{c}}$ Means within a row with different superscripts differ significantly $(P<0.05)$.

${ }^{1}$ Vacuum-packaged cheeses (VP); cheeses packaged under $100 \% \mathrm{~N}_{2}(\mathrm{NP})$; cheeses packaged under $20 \% \mathrm{CO}_{2} / 80 \% \mathrm{~N}_{2}(\mathrm{CN} 1 \mathrm{P})$; and cheeses packaged under $50 \% \mathrm{CO}_{2} / 50 \% \mathrm{~N}_{2}(\mathrm{CN} 2 \mathrm{P})$.

${ }^{2}$ Odor of packaged cheeses evaluated by smelling immediately after taking the samples out of the bags.

${ }^{3}$ Result of multiplying appearance by 1 , texture by 3 , and flavor by 6 .

1-one and 2-methyl-2-cyclopenten-1-one compounds, probably derived from smoke, were also detected in higher amounts in the $\mathrm{CO}_{2}$-treated cheeses and $\mathrm{NP}$ cheeses than in the control and VP cheeses.

The highest amounts $(P<0.05)$ of the esters ethyl acetate and ethyl hexanoate were found in the NP cheeses compared with the control cheeses (Table 4) but not relative to VP or $\mathrm{CO}_{2}$-treated cheeses. Colchin et al. (2001) also found higher concentrations of esters in cheeses stored under $\mathrm{N}_{2}$ relative to cheeses stored under $\mathrm{CO}_{2}(100 \%)$. The inhibitory effect of $\mathrm{CO}_{2}$ toward the formation of esters and other flavor compounds in cheeses has been reported by others (Colchin et al., 2001; Trobetas et al., 2008).

Sulfur compounds (dimethyl disulfide, dimethyl sulfide, and carbon disulfide) were detected at lower relative abundances in SSC, but the abundances were higher $(P<0.05)$ in control cheeses (Table 4$)$, suggesting that MAP treatments impose an inhibitory effect on microbial proteolysis (Adda et al., 1982; Yvon and Rijnen, 2001) during aging.

In general, aromatic and alicyclic hydrocarbons were found at lower amounts in SSC (excluding chloroform), although they were higher in $\mathrm{NP}$ cheeses and $\mathrm{CO}_{2}-$ treated cheeses (Table 4). The heterocyclic compounds 2-methylfuran, benzofuran, and pyrazine, together with ethylbenzene and 1,3,5-trimethylbenzene, were not detected in control cheeses or in VP cheeses. Pyrazine, which was only detected in $\mathrm{CO}_{2}$-treated cheeses, may be formed via the Maillard reaction during aging of the cheeses, but has also been found as a result of microbial action contributing positively to flavor when present at low concentrations (Curioni and Bosset, 2002).

\section{Sensory Analysis}

The SSC cheeses generally had a buttery, hazelnut, and smoky flavor that ranged from mild to piquant (data not shown), consistent with the standards of the
PDO council (MAPA, 2005). Cheeses before storage (time 0 ) were awarded a mean overall score of 64.0 , with mean scores of 6.4 for appearance, 5.8 for texture, and 6.7 for flavor (data not shown). However, after $45 \mathrm{~d}$ of storage, the sensorial scores of all treatments decreased (Table 5). In this study, it was arbitrarily considered that cheeses with an overall score below 40 should be rejected, and NP, CN1P, and $\mathrm{CN} 2 \mathrm{P}$ treatments (3 out of 4 treatments) resulted in scores below 40. The VP and control cheeses, which achieved higher scores for flavor and overall scores $(P<0.05)$ than the other cheeses (Table 5 ), were frequently ( 6 out of 10 panelists; data not shown) reported to have an intense buttery flavor (a positive characteristic in accordance with the PDO regulations). Nevertheless, although the mean abundance of diacetyl was higher in VP cheeses (467.2 relative abundance; data not shown), no differences $(P>0.05)$ were found for amounts of this compound among the groups of cheeses. The $\mathrm{CN} 2 \mathrm{P}$ cheeses were sometimes (4 out of 10 panelists; data not shown) defined as "sour" and "piquant" in taste, descriptors also used for other hard cheeses packaged under high concentrations of $\mathrm{CO}_{2}$ (Trobetas et al., 2008). The texture of NP and $\mathrm{CO}_{2}$-treated cheeses was frequently (7 out of 10 panelists; data not shown) defined as "granulous" or "friable," a feature that has also been observed in hard cheeses packaged under high concentrations of $\mathrm{CO}_{2}$ (Romani et al., 2002; Juric et al., 2003). On the contrary, the texture of VP cheeses was generally (8 out of 10 judges; data not shown) defined as "softer" and "more elastic," than that of control cheeses, perhaps closer to the "semi-elastic" descriptor proposed by the PDO regulations. Fat migration phenomena in VP cheese may be involved in the evolution toward a less friable and more elastic structure (Romani et al., 2002).

A relationship between flavor and the different biochemical traits analyzed throughout this study is shown by the main correlation coefficients in Table 6 . 
Table 6. Main correlations between flavor and chemical and biochemical parameters in San Simón da Costa industrial cheeses

\begin{tabular}{lc}
\hline Trait correlated with flavor & $\begin{array}{c}\text { Pearson correlation } \\
\text { coefficient }(\mathrm{r})\end{array}$ \\
\hline Free AA & $0.654^{*}$ \\
Aspartic acid & $0.675^{*}$ \\
Lysine & $0.651^{*}$ \\
Phenylalanine & $0.625^{*}$ \\
Total free AA & $-0.896^{* *}$ \\
Alcohols & $-0.784^{* *}$ \\
3-Methyl 1-butanol & $-0.773^{* *}$ \\
3-Methyl 2-butanol & \\
2-Ethyl-1-hexanol & $-0.610^{*}$ \\
Ketones and esters & $-0.604^{*}$ \\
2-Butanone & \\
Ethyl acetate & $-0.626^{*}$ \\
Compounds of smoke origin & $-0.922^{* *}$ \\
Furfural & $-0.664^{*}$ \\
Cyclopentanol & $-0.744^{* *}$ \\
1,3,5-Trimethylbenzene & $-0.698^{* *}$ \\
2-Methylfuran & $-0.744^{* *}$ \\
Pyrazine &
\end{tabular}

${ }^{*} P<0.05 ;{ }^{* *} P<0.01$.

Moreover, the hierarchical cluster analysis graphically assigned the VP cheeses as very close to control cheeses (Figure 1). Strong negative correlations for flavor with high statistical significance $(P<0.01)$ were found with branched-chain alcohols (3-methyl-1-butanol, 3-methyl-2-butanol, and 2-ethyl-1-hexanol) and compounds probably derived from smoke (cyclopentanol, 2-methylfuran, and pyrazine) (Table 6). When interpreting all of these correlations, it must be taken into account that the members of sensory panel who participated in this study were specifically trained to recognize the standards of industrial PDO cheeses; thus, flavors caused by compounds such as branched-chain aldehydes and alcohols would perhaps not be considered desirable or typical. Moreover, intense smoke odor because of the presence of higher quantities of compounds such as phenol, cyclopentanol, or 2-methyl-2-cyclopenten-1-one may be considered a negative feature.

\section{CONCLUSIONS}

Modified-atmosphere packaging appears to alter the ripening processes as regards lipolysis and proteolysis. The lower concentrations of butyric and propionic acids observed under MAP conditions may be attributed to a reduction in the degree of lipolysis. On the other hand, proteolysis yielded greater amounts of branchedchain alcohols, which were negatively correlated with flavor. Storage under modified atmospheres for a period simulating distribution and retail conditions appears to

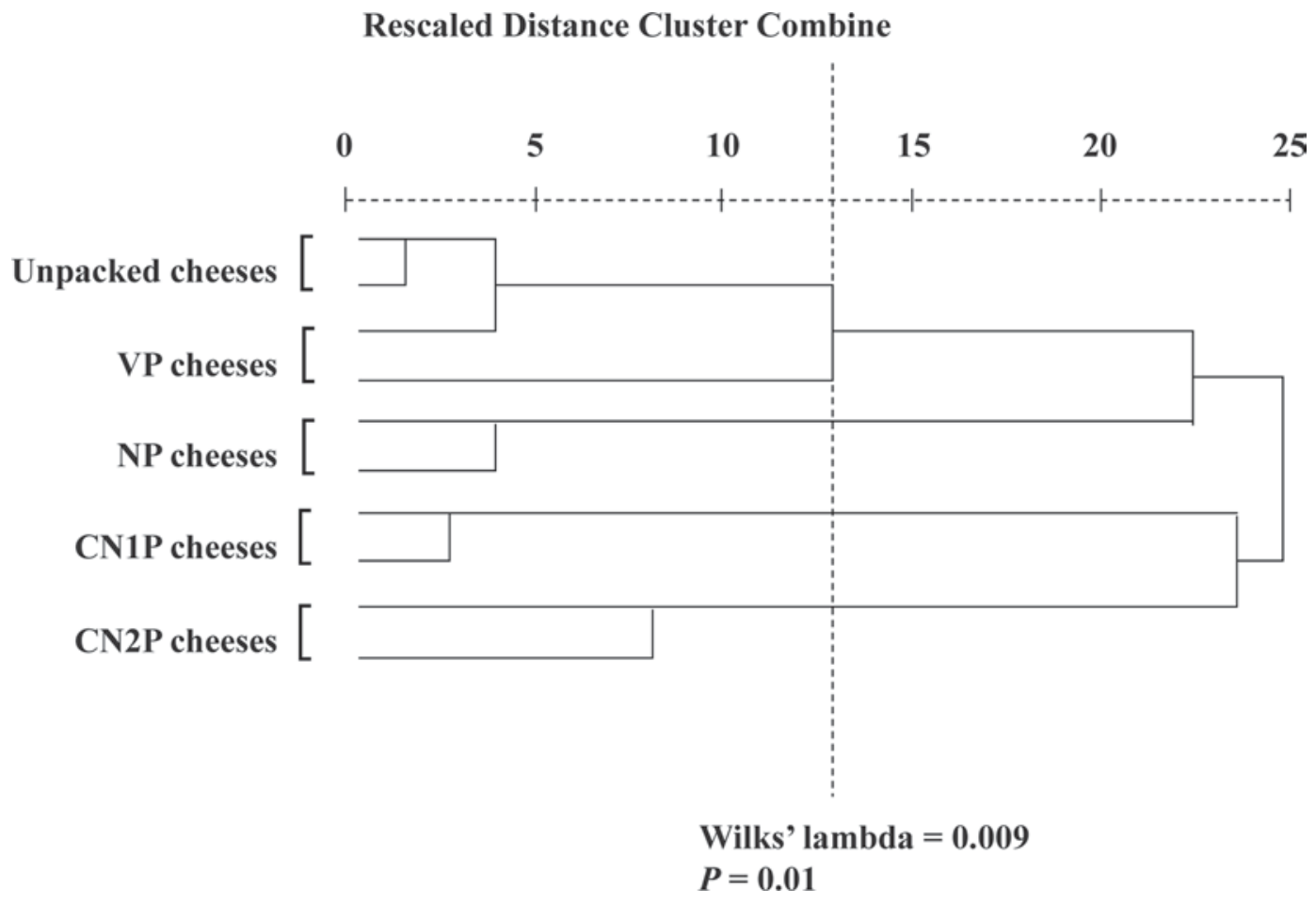

Figure 1. Hierarchical cluster analysis generated from the chemical and biochemical traits that were correlated with flavor after $45 \mathrm{~d}$ of storage: vacuum-packaged cheese (VP cheeses); cheese packaged under $100 \% \mathrm{~N}_{2}$ (NP cheeses); cheese packaged under $20 \% \mathrm{CO}_{2} / 80 \% \mathrm{~N}_{2}(\mathrm{CN} 1 \mathrm{P}$ cheeses), and cheese packaged under $50 \% \mathrm{CO}_{2} / 50 \% \mathrm{~N}_{2}$ (CN2P cheeses). The dashed line indicates the level of statistical significance of discrimination between unpackaged/VP cheeses and NP/CN1P/CN2P cheeses. 
contribute to the accumulation of smoke-derived compounds within the cheese, which were also negatively correlated with flavor. For a storage period of up to $45 \mathrm{~d}$, vacuum packaging appears to be the most useful technique for preserving the sensory quality of SSC cheeses.

\section{ACKNOWLEDGMENTS}

We are grateful to Raquel Lage (CIAM, Abegondo, Spain) for skilful technical assistance. The authors thank the members of the Sensory Panel of the Regulatory Consortium of Galician cheeses with Protected Designation of Origin, in particular to Angel Ramil Castelo from the SSC PDO Council, for their assistance in carrying out the expert sensorial analysis. This study was financially supported by the Xunta de Galicia, Spain, and FEDER-MAC funds (project PGIDIT02TAL50301PR and grants PGIDIT03PXIC50301PN -PGIDT06PXIC503085PN). P. Rodríguez-Alonso acknowledges the receipt of a research fellowship from the Instituto Nacional de Investigación y Tecnología Agraria y Alimentaria, Spain (INIA) during these studies.

\section{REFERENCES}

Adda, J., J. C. Gripon, and L. Vassal. 1982. The chemistry of flavor and texture generation in cheese. Food Chem. 9:115-129.

Akalin, A. S., S. Gönç, and I. Y. Akba. 2002. Variation in organic acids content during ripening of pickled white cheese. J. Dairy Sci. 85:1670-1676.

AOAC. 1990. Official Methods of Analysis. 15th ed. Association of Official Analytical Chemists, Arlington, VA.

Barron, L. J. R., Y. Redondo, M. Aramburu, P. Gil, F. J. PérezElortondo, M. Albisu, A. I. Nájera, M. Renobales, and E. Fernández-García. 2007. Volatile composition and sensory properties of industrially produced Idiazabal cheese. Int. Dairy J. 17:1401-1414.

Battistotti, B., and C. Corradini. 1993. Italian Cheese. Pages 221-243 in Cheese: Chemistry, Physics and Microbiology. Vol. 2. P. F. Fox, ed. Chapman and Hall, London, UK.

Bertozzi, L., and G. Panari. 1993. Cheese with appellation d'origine contrôlé (AOC): Factors that affect quality. Int. Dairy J. 3:297312 .

Bevilacqua, A. E., and A. N. Califano. 1989. Determination of organic acids in dairy products by high performance liquid chromatography. J. Food Sci. 54:1076-1079.

Bugaud, C., S. Buchin, A. Hauwuy, and J. B. Coulon. 2001. Relationships between flavor and chemical composition of Abondance cheese derived from different types of pastures. Lait 81:757-773.

Califano, A. N., and A. E. Bevilacqua. 2000. Multivariate analysis of the organic acids content of Gouda type cheese during ripening. J. Food Compost. Anal. 13:949-960.

Colchin, L. M., S. L. Owens, G. Lyubachevskaya, E. Boyle-Roden, E. Russek-Cohen, and S. A. Rankin. 2001. Modified atmosphere packaged Cheddar cheese shreds: Influence of fluorescent light exposure and gas type and production of volatile compounds. J. Agric. Food Chem. 49:2277-2282.

Curioni, P. M. G., and J. O. Bosset. 2002. Key odorants in various cheese types as determined by gas chromatography-olfactometry. Int. Dairy J. 12:959-984.
Dermiki, M., A. Ntzimani, A. Badeka, I. N. Savvaidis, and M. G. Kontominas. 2008. Shelf-life extension and quality attributes of the whey cheese 'Myzithra Kalathaki' using modified atmosphere packaging. LWT Food Sci. Technol. 41:284-294.

Eliot, S. C., J. C. Vuillemard, and J. P. Edmond. 1998. Stability of shredded Mozzarella cheese under modified atmospheres. J. Food Sci. 63:1075-1080.

Fallico, V., P. L. H. Mcsweeney, K. J. Siebert, J. Horne, S. Carpino, and G. Licitra. 2004. Chemometric analysis of proteolysis during ripening of Ragusano cheese. J. Dairy Sci. 87:3138-3152.

Félix, J. S., M. Monteiro, J. E. Manzoli, M. Padula, D. Pezo, J. Romero, and C. Nerín. 2008. Identification and migration of degradation compounds from irradiation of multilayer polyamide 6 films for meat foodstuffs and cheese. Anal. Bioanal. Chem. 391:847-857.

Franceschi, V. R., and P. A. Nakata. 2005. Calcium oxalate in plants: Formation and function. Annu. Rev. Plant Biol. 56:41-71.

Garabal, J. I., P. Rodríguez-Alonso, and J. A. Centeno. 2008 Preliminary characterization of lactic acid bacteria isolated from raw cows' milk cheeses currently produced in Galicia (NW Spain). LWT Food Sci. Technol. 41:1452-1458.

García-Fontán, M. C., I. Franco, B. Prieto, M. E. Tornadijo, and J. Carballo. 2001. Microbiological changes in "San Simón" cheese throughout ripening and its relationship with physico-chemical parameters. Food Microbiol. 18:25-33.

González-de Llano, D., A. Rodríguez, and P. Cuesta. 1996. Effect of lactic starter cultures on the organic acid composition of milk and cheese during ripening-Analysis by HPLC. J. Appl. Microbiol. 80:570-576.

González-Fandos, E., S. Sanz, and C. Olarte. 2000. Microbiological, physicochemical and sensory characteristics of Cameros cheese packaged under modified atmospheres. Food Microbiol. 17:407414.

Gorostiza, A., A. J. Cichoscki, A. T. Valduga, E. Valduga, A. Bernardo, and J. M. Fresno. 2004. Changes in soluble nitrogenous compounds, caseins and free amino acids during ripening of artisanal Prato cheese, a Brazilian semi-hard cow's variety. Food Chem. 85:407-414.

Gummalla, S., and J. R. Broadbent. 2001. Tyrosine and phenylalanine catabolism by Lactobacillus cheese flavor adjuncts. J. Dairy Sci. 84:1011-1019.

Hotchkiss, J. H., B. G. Werner, and E. Y. C. Lee. 2006. Addition of carbon dioxide to dairy products to improve quality: A comprehensive review. Comp. Rev. Food Sci. Food Saf. 5:158168.

IDF (International Dairy Federation). 1982. Cheese and processed cheese-Determination of total solids content. IDF Standard 4A. IDF, Brussels, Belgium.

IDF (International Dairy Federation). 1986. Determination of nitrogen content (Kjeldahl method) and calculation of crude protein content. IDF Standard 20A. IDF, Brussels, Belgium.

IDF (International Dairy Federation). 1996. Milk and milk productsPreparation of samples and dilutions for microbiological examination. IDF Standard 122C. IDF, Brussels, Belgium.

IDF (International Dairy Federation). 1997a. Milk and milk productsDetermination of fat content. IDF standard 152A. IDF, Brussels, Belgium.

IDF (International Dairy Federation). 1997b. Sensory evaluation of dairy products. IDF standard 99C. IDF, Brussels, Belgium.

International Organization for Standardization (ISO). 1994. Sensory analysis. General guidance for the selection, training and monitoring of assessors-Part 2: Experts. ISO 8586-2:1994. ISO, Geneva, Switzerland.

Jónsdóttir, R., G. Ólafsdóttir, E. Chanie, and J.-E. Haugen. 2008 Volatile compounds suitable for rapid detection as quality indicators of cold smoked salmon (Salmo salar). Food Chem. 109:184-195.

Juric, M., G. Bertelsen, G. Mortensen, and M. A. Petersen. 2003. Lightinduced colour and aroma changes in sliced, modified atmosphere packaged semi-hard cheeses. Int. Dairy J. 13:239-249.

Kristensen, D., V. Orlien, G. Mortensen, P. Brockhoff, and L. H Skibsted. 2000. Light-induced oxidation in sliced Havarti cheese packaged in modified atmosphere. Int. Dairy J. 10:95-103. 
Larson, B. L., and H. M. Hegarty. 1979. Orotic acid in milks of various species and commercial dairy products. J. Dairy Sci. 62:16411644.

Lemieux, L., and E. R. Simard. 1992. Bitter flavor in dairy products. II. A review of bitter peptides from caseins: Their formation, isolation and identification, structure masking and inhibition. Lait 72:335-382.

Lues, J. F. R., and A. C. M. Bekker. 2002. Mathematical expressions for organic acids in early ripening of a Cheddar cheese. J. Food Compos. Anal. 15:11-17.

Maga, J. A. 1988. Smoke in food processing. Pages 49-86. CRC Press, Boca Ratón, FL.

Marshall, V. M., and W. M. Cole. 1983. Threonine aldolase and alcohol dehydrogenase activities in Lactobacillus bulgaricus and Lactobacillus acidophilus and their contribution to flavor production in fermented milks. J. Dairy Res. 50:375-379.

MAPA (Ministerio de Agricultura, Pesca y Alimentación). 2005. Reglamento de la Denominación de Origen Protegida 'San Simón da Costa' y de su Consejo Regulador. Bol. Off. Estado Spain 128:18147-18153.

Nhuch, E. L., B. Prieto, I. Franco, A. Bernardo, and J. Carballo. 2008a. Biochemical changes during the ripening of homemade "San Simón da Costa" raw milk cheese. Int. J. Dairy Technol. 61:80-89.

Nhuch, E. L., B. Prieto, I. Franco, A. Bernardo, and J. Carballo. 2008b. Biochemical changes during the ripening of "San Simón da Costa" (PDO) manufactured from pasteurised milk. Aust. J. Dairy Technol. 63:68-76.

Pappa, E. C., and K. Sotirakoglou. 2008. Changes of free amino acid content of Teleme cheese made with different types of milk and culture. Food Chem. 111:606-615.

Polo, C., M. Ramos, and R. Sánchez. 1985. Free amino acids by high performance liquid chromatography and peptides by gel electrophoresis in Mahon cheese during ripening. Food Chem. 16:85-96.

Robertson, G. L. 1993. Food Packaging: Principles and Practice. Marcel Dekker Inc., New York, NY.

Rodríguez-Alonso, P., J. A. Centeno, and J. I. Garabal. 2009. Comparison of the volatile profiles of Arzúa-Ulloa and Tetilla cheeses manufactured from raw and pasteurized milk. Lebensm. Wiss. Technol. 42:1722-1728.

Rodríguez-Alonso, P., J. I. Garabal, and J. A. Centeno. 2008. Preliminary characterization of staphylococcal, micrococcal and yeast isolates obtained from raw cows' milk cheeses currently produced in Galicia (NW Spain). Ital. J. Food Sci. 2:161-169.

Romani, S., G. Sacchetti, P. Pittia, G. G. Pinnavaia, and M. Dalla Rosa. 2002. Physical, chemical, textural and sensorial changes of portioned Parmigiano Reggiano cheese packed under different conditions. Food Sci. Technol. Int. 8:203-211.

Rychlik, M., P. Schieberle, and W. Grosch. 1998. Compilation of odour thresholds, odour qualities and retention indices of keyfood odorants. Garching: Deutsche Forschungsanstalt für Lebensmittelchemie and Institut für Lebensmittelchemie der Technischen Universität München, Germany.

Skeie, S., A. Kieronczyk, R. M. Næss, and H. Østli. 2007. Lactobacillus adjuncts in cheese: Their influence on the degradation of citrate and serine during ripening of a washed curd cheese. Int. Dairy J. 18:158-168.

Tormo, M., and J. M. Izco. 2004. Alternative reversed-phase highperformance liquid chromatography method to analyse organic acids in dairy products. J. Chromatogr. A 1033:305-310.

Trobetas, A., A. Badeka, and M. G. Kontominas. 2008. Light-induced changes in grated Graviera hard cheese packaged under modified atmospheres. Int. Dairy J. 18:1133-1139.

Turner, K. W., and T. D. Thomas. 1980. Lactose fermentation in Cheddar cheese and the effect of salt. N.Z. J. Dairy Sci. Tech. 15:265-276.

Upreti, P., L. L. McKay, and L. E. Metzger. 2006. Influence of calcium and phosphorus, lactose, and salt-to-moisture ratio on Cheddar cheese quality: Changes in residual sugars and water-soluble organic acids during ripening. J. Dairy Sci. 89:429-443.

Urbach, G. 1993. Relations between cheese flavor and chemical composition. Int. Dairy J. 3:389-422.

Van Wandelen, C., and S. A. Cohen. 1997. Using quaternary highperformance liquid chromatography eluent systems for separating 6-aminoquinolyl-N-hydroxysuccinimidyl carbamate-derivatized amino acid mixtures. J. Chromatogr. A 763:11-22.

Vercelino, R. M., C. I. Grícoli de Luca, A. Gimenes, and J. Fonseca. 1996. Stability of sliced mozzarella in modified-atmosphere packaging. J. Food Prot. 59:838-844.

Yvon, M., and L. Rijnen. 2001. Cheese flavor formation by amino acid catabolism. Int. Dairy J. 11:185-201. 